\title{
Stoichiometric Analysis of Inorganic Compounds Using Laser-Induced Breakdown Spectroscopy with Gated and Nongated Spectrometers
}

\author{
Sreedhar Sunku, Ashwin Kumar Myakalwar, Manoj Kumar Gundawar, Prem Kiran Paturi, \\ Surya Praksh Tewari, and Venugopal Rao Soma
} Advanced Centre of Research in High Energy Materials (ACRHEM), University of Hyderabad, Prof. C.R. Rao Road,
Hyderabad 500046, India

Correspondence should be addressed to Manoj Kumar Gundawar, manojsp@uohyd.ernet.in and Venugopal Rao Soma, soma_venu@yahoo.com

Received 13 March 2012; Accepted 3 April 2012

Academic Editors: J. S. Sanghera and S. F. Yu

Copyright () 2012 Sreedhar Sunku et al. This is an open access article distributed under the Creative Commons Attribution License, which permits unrestricted use, distribution, and reproduction in any medium, provided the original work is properly cited.

\begin{abstract}
We describe our results obtained from stoichiometric ratio studies of three different energetic, inorganic samples (ammonium perchlorate (AP), boron potassium nitrate (BPN), and ammonium nitrate (AN)) using the technique of laser-induced breakdown spectroscopy (LIBS) with nanosecond pulses. Signal collection was independently executed using both gated and nongated spectrometers. The oxygen peak at $777.31 \mathrm{~nm}(\mathrm{O})$ and nitrogen peaks at $742.50 \mathrm{~nm}\left(\mathrm{~N}_{1}\right), 744.34 \mathrm{~nm}\left(\mathrm{~N}_{2}\right)$, and $746.91 \mathrm{~nm}\left(\mathrm{~N}_{3}\right)$ were used for evaluating the $\mathrm{O} / \mathrm{N}$ ratios. Temporal analysis of plasma parameters and ratios was carried out for the gated data. $\mathrm{O} / \mathrm{N}_{1}, \mathrm{O} / \mathrm{N}_{2}$, and $\mathrm{O} / \mathrm{N}_{3}$ ratios retrieved from the gated $\mathrm{AP}$ data were in excellent agreement with the actual stoichiometry. In the case of gated $\mathrm{BPN}$ data, $\mathrm{O} / \mathrm{N}_{2}$ and $\mathrm{O} / \mathrm{N}_{3}$ ratios were in good agreement. The stoichiometry results obtained with nongated spectrometer, although less accurate than that obtained with gated spectrometer, suggest that it can be used in applications where fair accuracy is sufficient. Our results strongly indicate that non-gated LIBS technique is worthwhile in the kind of applications where precision classification is not required.
\end{abstract}

\section{Introduction}

Nanosecond (ns) laser-induced breakdown spectroscopy (LIBS) has been extensively employed in elemental analysis, impurity detection $[1,2]$, and identification/classification of materials $[3,4]$. In recent years this technique has been applied to study a variety of materials such as alloys, biological samples, pharmaceuticals, and explosives amongst various others [5-8]. The strength of this technique emanates from prerequisites that an ideal analytical tool should possess - minimal sample preparation, simultaneous multielement detection, ability to analyze all three states of matter, the necessity of short-time scales involved for measurement and analysis, and most importantly the capability of remote detection. In most of the cases requirement for sample preparation is negligible. This technique involves the interaction of an intense laser pulse with a sample leading to plasma generation [9-12]. The material absorbs light through multiphoton/inverse Bremsstrahlung process that heats the sample surface further to which electrons acquire energy, and as the energy absorbed grows, it leads to collisions and breakdown. Breakdown is followed by the plasma expansion and consequently the creation of shock waves. The plasma expansion rate is observed to be highest towards the focusing lens [13]. During the cooling stage constituent ions/electrons of expanding plasma recombine to form neutral atoms, and some may combine to form molecules. The energy difference appears as light and heat. The light is collected through an optical fiber connected to spectrometer, and is known as the LIBS signal. The LIBS signal evolves rapidly in time and can be divided into two regimes. In the first few hundreds of nanoseconds, 
the signal is dominated by a broad white light Continuum with sharp peaks overriding it. The origin of the continuum is attributed to Bremsstrahlung and the recombination radiation. The sharp peaks seen in LIBS spectra are signatures of atomic/molecular transitions. After about few hundreds of ns, the Continuum dies down and signal consists of only sharp peaks, which are the signatures of species present in the sample. In order to achieve an excellent signal to background ratio, the data is generally collected with a few 100 ns delay with respect to the exciting laser pulse. However, there have been few reports where a nongated detection scheme was also employed $[2,14-16]$ for recording the spectra. The use of a nongated spectrometer is enticing since it can provide rapid means of studying the stoichiometry of various compounds and thereby eliminating unwanted compounds during the detection of hazardous materials. Though the signal to background ratio is less in the case of nongated detection, compared to that of gated scheme, its use in instrumentation can help cut down the operating expenses drastically. Nongated technique is very easy to operate for a nontechnical person since the light collection part of the experimental scheme is very simple.

High energy materials (HEM's) are soft organic compounds with the general formula $\mathrm{C}_{\alpha} \mathrm{H}_{\beta} \mathrm{N}_{\gamma} \mathrm{O}_{\nu}$. The dominant peaks in the LIBS spectra of all such compounds comprise of carbon, hydrogen, oxygen, and nitrogen. It is, therefore, extremely difficult to distinguish between HEM's and other simple organic materials simply based on the LIBS data. In spite of such an intricacy, Rai et al. $[17,18]$ in a recent study, with nitro molecules, demonstrated that organic nitrocompounds 4-nitroaniline and 4-nitrotoluene can be identified through their stoichiometry by simply measuring the $\mathrm{O} / \mathrm{N}$ ratios from their corresponding LIBS spectral data. It has been established that the use of LIBS for identification of compounds on an operational level requires extensive developments in two directions (a) determination of stoichiometry of a particular compound by using intensity ratios of spectral lines of one or more pairs of elements [18-20] and (b) matching the unknown spectrum with predetermined and assembled spectral library of reference materials of interest. This particular method was employed by de Lucia and Gottfried [21] along with other elemental ratios calculation as part of an algorithm to discriminate explosives and achieved good success. Several other LIBS studies involving stoichiometric approaches have also been reported recently in the literature [22-28]. There have been numerous other efforts over the last decade on LIBS studies of HEM's and other hazardous materials for identification/classification [29-34]. In this paper, LIBS studies on inorganic compounds such as ammonium perchlorate $\left(\mathrm{AP}, \mathrm{NH}_{4} \mathrm{ClO}_{4}\right)$, boron potassium nitrate mixture $\left(\mathrm{BPN}, \mathrm{BKNO}_{3}\right)$, and ammonium nitrate $\left(\mathrm{AN}, \mathrm{NH}_{4} \mathrm{NO}_{3}\right)$ are reported wherein the comparison of $\mathrm{O} / \mathrm{N}$ ratios was evaluated in order to evaluate the performance of nongated detection scheme vis-à-vis a gated detection method. Based on these ratios one could easily perform an initial screening of materials for differentiating nitrogen-containing (hazardous) compounds from other organic/inorganic (safe) compounds. After successful initial screening, one could further develop powerful algorithms based on other atomic/molecular line intensity ratios for the fool-proof discrimination of HEM's.

\section{Experimental Details}

AP $\left(\mathrm{NH}_{4} \mathrm{ClO}_{4}\right), \mathrm{BPN}\left(\mathrm{BKNO}_{3}\right)$, and $\mathrm{AN}\left(\mathrm{NH}_{4} \mathrm{NO}_{3}\right)$ mixtures are principal raw materials for composite propellants used in modern rocket engines as oxidizers. They become explosive when mixed with finely divided organic materials. Rapid and simple techniques for identification of such molecules are essential to prevent untoward incidents. Circular pellets of $\sim 20 \mathrm{~mm}$ diameter were prepared by filling the sample in a die and then applying a pressure of eight tones for a period of twenty minutes. The samples were mounted on a linear X-Y translation motorized stage to ensure that subsequent laser pulse hits a fresh portion of the sample. Laser pulses with energies in the range of $25-45 \mathrm{~mJ}$ from a second harmonic of Nd:YAG laser at $532 \mathrm{~nm}$ ( $7 \mathrm{~ns}$ pulse width, $10 / 5 \mathrm{~Hz}$ repetition rate) were focused on to the sample using an $80 \mathrm{~mm}$ convex lens. The sample surface was kept at a distance of $1 \mathrm{~mm}$ before the focus such that the peak intensities used were below the breakdown threshold of air thereby avoiding the breakdown of ambient air and prevents its contribution to the LIBS signal. In spite of these experimental conditions we could expect some contribution from air to the total LIBS signal thereby affecting the $\mathrm{O} / \mathrm{N}$ ratios and therefore we purged the experimental setup (sample region, especially) with dry Argon gas. We have performed the experiments with nongated spectrometer in argon atmosphere and gated spectrometer in ambient air. The signal was collected using a lens system and was coupled into a fiber attached to a spectrometer. The nongated spectrometer (Ocean Optics, MAYA 2000, spectral sensitivity 200-1100 nm range) has a spectral resolution of $\sim 1.2 \mathrm{~nm}$ while the gated spectrometer (ANDOR, Mechelle spectrograph ME5000, coupled to an ANDOR iSTARDH734ICCD, spectral sensitivity $200 \mathrm{~nm}-900 \mathrm{~nm}$ range, and resolving power of 5000) had $\sim 0.15 \mathrm{~nm}$. The spectral resolution was measured as full-width half maximum (FWHM) of a Helium-Neon laser line at $632.8 \mathrm{~nm}$. Figure 1 shows the typical experimental setup for LIBS collection using a gated spectrometer. The gated spectrometer was replaced with MAYA spectrometer for the nongated detection scheme. In the gated case, spectra were recorded with different gate delays in the range of $100 \mathrm{~ns}-1900 \mathrm{~ns}$. The Pockel cell's output of the laser triggered a SRS delay generator, which in turn provided a TTL pulse to trigger the ICCD.

\section{Results and Discussion}

Figure 2 illustrates the LIBS spectra of AP, BPN, and AN samples accumulated over ten acquisitions collected with gated spectrometer with $1000 \mathrm{~ns}$ gate width and $1000 \mathrm{~ns}$ gate delay. Figure 3 demonstrates the spectrum obtained with nongated spectrometer collected with an integration time of $200 \mathrm{msec}$. The spectral region $(700 \mathrm{~nm}-900 \mathrm{~nm})$ relevant to the stoichiometric calculations is only shown in the figure. The spectra recorded with nongated spectrometers 


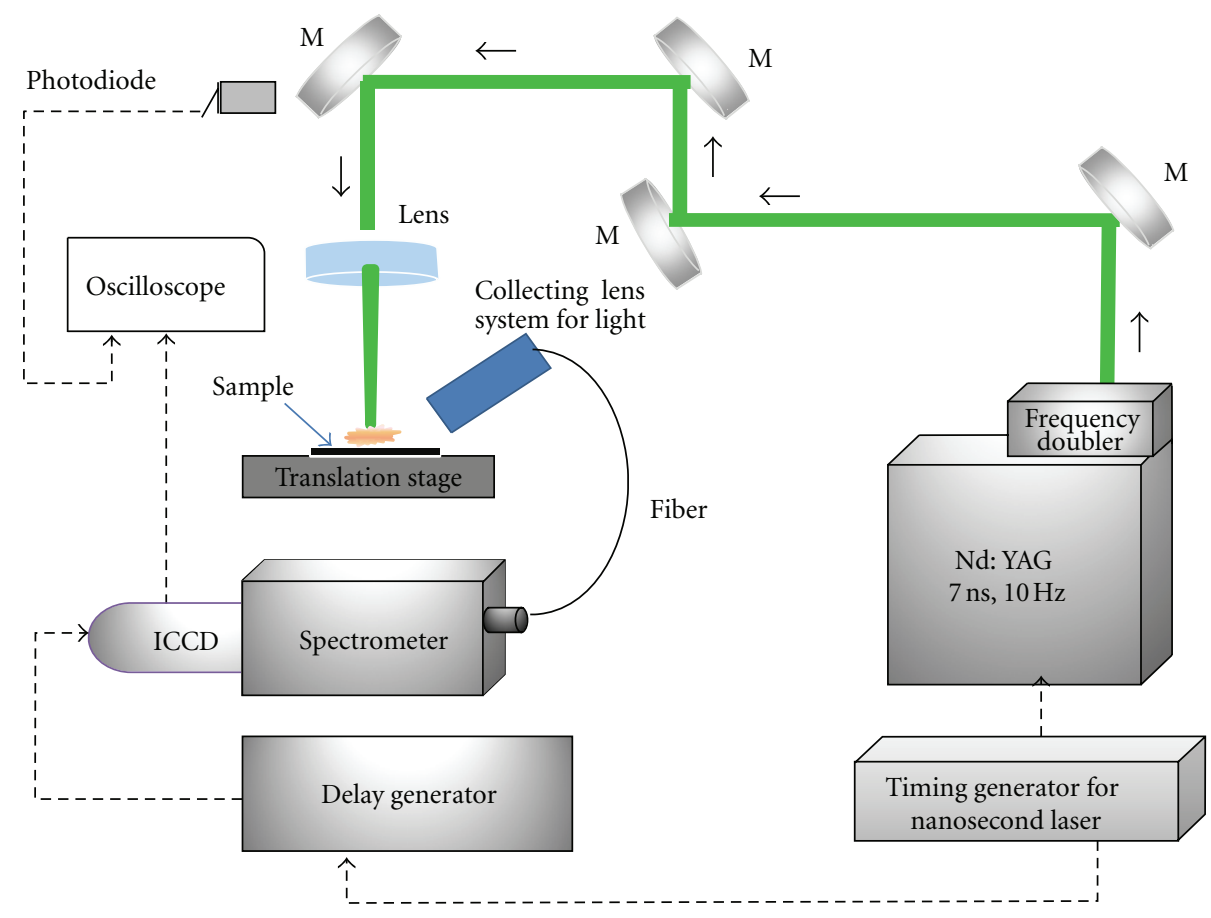

FIgURE 1: Typical LIBS experimental setup.

demonstrated a continuum background as the collected signal was a result of $200 \mathrm{~ms}$ accumulation time. The continuum background was subtracted from the data using a simple Matlab program. The peaks have been assigned to different neutral and ionic states using the NIST database [35]. In particular, all the spectra exhibited peaks corresponding to nitrogen, oxygen and hydrogen with the both the spectrometers. Observed peaks and their wavelengths are tabulated in Table 1. Additionally, peaks corresponding to transitions within excited nitrogen $(396.84 \mathrm{~nm}, 399.50 \mathrm{~nm}$, $500.20 \mathrm{~nm}$, and $567.16 \mathrm{~nm}$ ) were observed with the nongated spectrometers and with the gated spectrometer for smaller delays. The peak widths were much sharper in case of gated detection due to higher resolving power. Moreover, the gated spectrometer enabled the recording of time evolution of LIBS signal. A typical time evolution data is presented in Figure 4 for the sample AP using a gate width of $200 \mathrm{~ns}$ and for various delays in the range of $100 \mathrm{~ns}$ to $1900 \mathrm{~ns}$. During the first five hundred ns of detection, the signal was dominated by Continuum and sharp ionic peaks. Subsequently, the continuum subsided, and signal was dominated by atomic peaks. The time evolution of oxygen peak (at $777.31 \mathrm{~nm}$ ) and Nitrogen peak (at $746.91 \mathrm{~nm}$ ) for three samples is shown in Figure 5. The decay has been approximated to a single exponential. The decay constants of both these lines (O777.31 and $\mathrm{N}-746.91 \mathrm{~nm}$ ) were found to be $\sim 0.36-0.44 \mu \mathrm{s}$ and $\sim 0.23-0.29 \mu \mathrm{s}$, respectively, for all the samples. As the evolution of both species followed similar dynamics, no corrections were needed when their ratios were evaluated. A drastic difference in the decay constants would lead to incorrect values of the ratios, and corrections need to be incorporated in such a scenario. We have calculated the intensity decay constants of other peaks of Oxygen, Nitrogen, and Hydrogen for all the three samples and data is summarized in Table 2. The estimation of plasma temperature was performed considering the Nitrogen peaks observed in the LIBS spectrum with gated spectrometer. Figure 6 shows a typical Saha-Boltzmann plot obtained for AP with a gate delay of $1300 \mathrm{~ns}$ and $200 \mathrm{~ns}$ gate width. The plasma temperature was estimated to be $\sim 5173^{\circ} \mathrm{K}$. The temperatures estimated for all the three samples with variation in time delay are shown in Figure 7(a). Estimation of the electron density was done with Oxygen peak at $777.31 \mathrm{~nm}$. Typical values of densities obtained were $\sim 10^{17} \mathrm{~cm}^{-3}$. Figure $7(\mathrm{~b})$ shows the variation of electron density with delay time for all the three samples. The procedure for calculating electron density was followed using the procedure from references $[10,11]$. The time evolution of plasma parameters (temperature and electron density) indicates that the cooling time and electron density decreased with time, which is clearly depicted in Figure 7.

The Oxygen peak at $777.31 \mathrm{~nm}(\mathrm{O})$ and Nitrogen peaks at $742.50 \mathrm{~nm}\left(\mathrm{~N}_{1}\right), 744.34 \mathrm{~nm}\left(\mathrm{~N}_{2}\right)$, and $746.91 \mathrm{~nm}\left(\mathrm{~N}_{3}\right)$ were used for evaluating the $\mathrm{O} / \mathrm{N}$ ratios. While the Oxygen lines were not resolved, the $\mathrm{N}$ triplet was partially resolved with the nongated spectrometers and fully resolved with the gated spectrometer. With the nongated spectrometer, we could clearly resolve only $\mathrm{N}_{2}$ and $\mathrm{N}_{3}$ peaks $\left(\mathrm{N}_{1}\right.$ peak had less number of points and was discarded for further analysis) and, therefore, were used for fitting and extracting the area under the curves. Typical plots pertaining to Lorentzian fits of the peaks of Oxygen and Nitrogen, obtained with nongated spectrometer, are depicted in Figures 8(a) and 8(b), respectively. The corresponding data for gated spectrometer is presented in Figures $8(\mathrm{c})$ and $8(\mathrm{~d})$. Three different $\mathrm{O} / \mathrm{N}$ ratios were calculated for the gated data using three peaks 


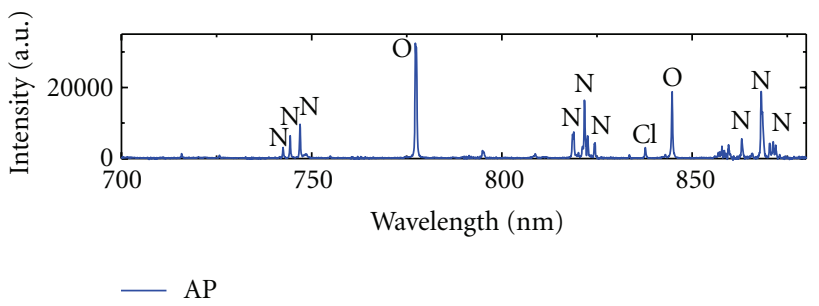

(a)

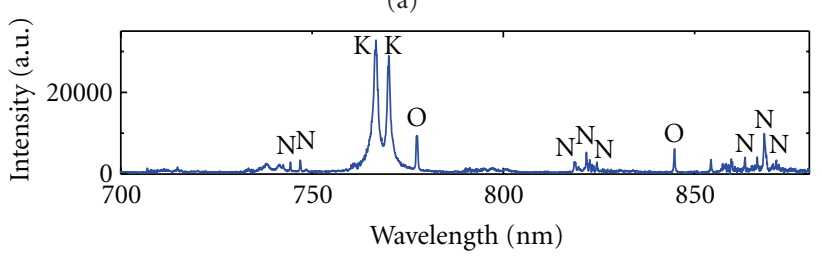

(b)

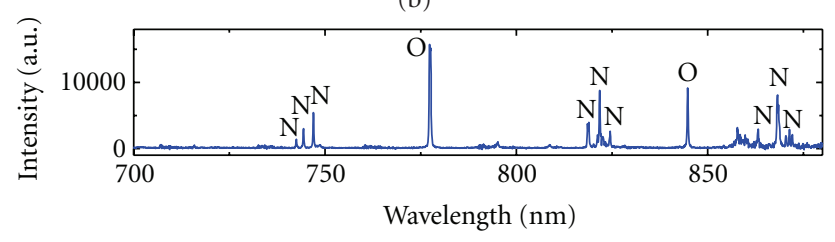

$-\mathrm{AN}$

(c)

FIGURE 2: LIBS spectra recorded with gated ICCD spectrometer with acquisition of 10 spectra recorded with 1000 ns gate width and 1000 ns gate delay.

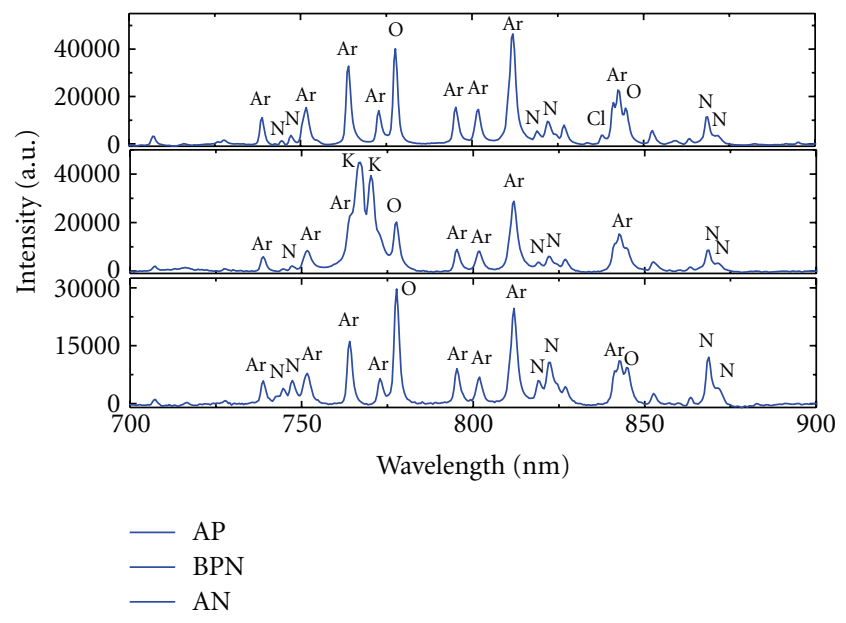

FIGURE 3: LIBS spectra recorded with a nongated spectrometer with an integration time of $200 \mathrm{~ms}$.

of nitrogen $\left[\mathrm{O} / \mathrm{N}_{1}, \mathrm{O} / \mathrm{N}_{2}\right.$ and $\left.\mathrm{O} / \mathrm{N}_{3}\right]$. A direct evaluation of the $\mathrm{O} / \mathrm{N}$ intensities by considering the area under the peaks resulted in very large values. The intensity of the specific atomic peak is dependent on the several parameters such as number densities, temperature, partition function, transition probability, and statistical weight corresponding to that line. Consequently, the parameters like transition

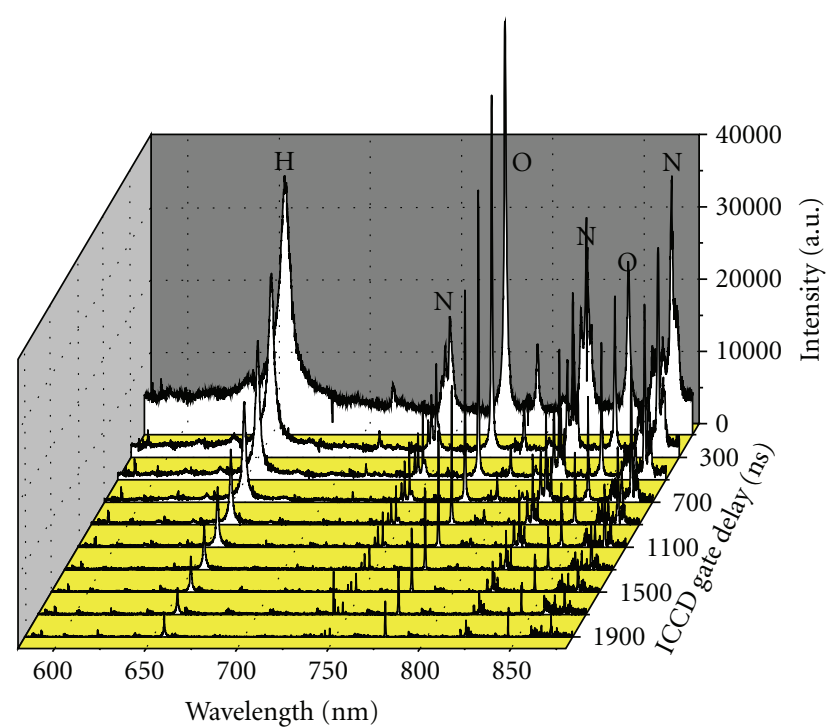

FIGURE 4: Time evolution LIBS spectra of AP with a gate width of $200 \mathrm{~ns}$ and delay in the range of 100-1900 ns.

TABLE 1: Different elemental peaks observed in the LIBS spectra of $\mathrm{AN}, \mathrm{BPN}$, and AN with both gated and non-gated spectrometers.

\begin{tabular}{ll}
\hline Element & $\begin{array}{l}\text { Corresponding peak obtained LIBS spectrum of } \\
\text { AP, BPN, and AN (nm) }\end{array}$ \\
\hline $\mathrm{C}$ & 247.86 \\
$\mathrm{Fe}$ & $250.69,251.63,251.94,252.42,422.71,516.78$, \\
$\mathrm{Mg}^{+}$ & $517.33,518.42$ \\
$\mathrm{Mg}_{\mathrm{Ca}}$ & $279.57,280.28$ \\
$\mathrm{Ca}^{+}$ & $285.27,288.19,383.24,383.83$ \\
$\mathrm{Ca}$ & $393.39,396.19$, \\
$\mathrm{Al}$ & 616.3 \\
$\mathrm{Na}$ & $394.43,396.88$ \\
$\mathrm{H}$ & $589.05,589.64$ \\
$\mathrm{~K}$ & 656.20 \\
$\mathrm{~N}$ & $766.76,770.07$ \\
$\mathrm{O}$ & $742.50,744.34,746.91,818.5,818.80,821.69$, \\
$\mathrm{Cl}$ & $824.41,859.65,865.64,868.38,871.36,871.94$ \\
\hline
\end{tabular}

probability and statistical weight were included in ratio calculations. This is comprehensible since the density of species is represented by $I_{i j} / \mathrm{A}_{i j} \mathrm{~g}_{i}$, where $I_{i j}$ is the observed area under the peak. Since the O line was not resolved fully, we divided the observed intensity into three parts based on the counts as reported in NIST database. The ratio of $I_{i j} / \mathrm{A}_{i j} \mathrm{~g}_{i}$ corresponding to $\mathrm{O}$ has then been, totaled and $I_{i j} / \mathrm{A}_{i j} \mathrm{~g}_{i}$ ratio value was obtained individually for $\mathrm{N}_{1}, \mathrm{~N}_{2}$, and $\mathrm{N}_{3}$. This totaled $\mathrm{O}$ value was used to obtain $\mathrm{O} / \mathrm{N}_{1}, \mathrm{O} / \mathrm{N}_{2}$, and $\mathrm{O} / \mathrm{N}_{3}$ ratios. Table 3 summarizes the ratios obtained using the gated and nongated spectrometer.

We have calculated all the three $\mathrm{O} / \mathrm{N}$ ratios with variation of time delay. Figure 9 depicts the time evolution of ratios 


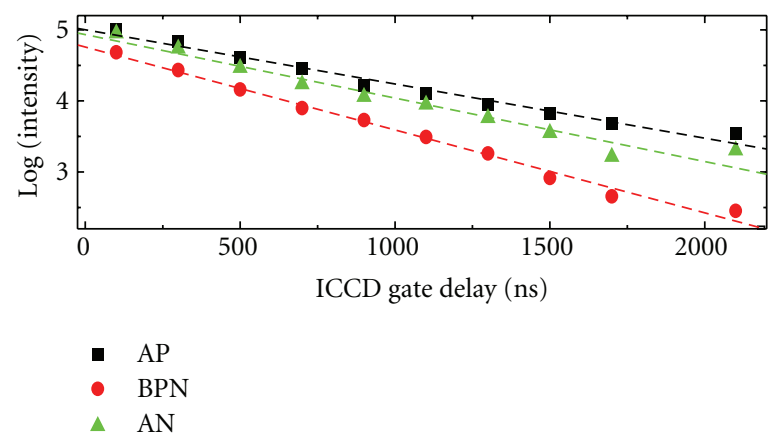

(a)

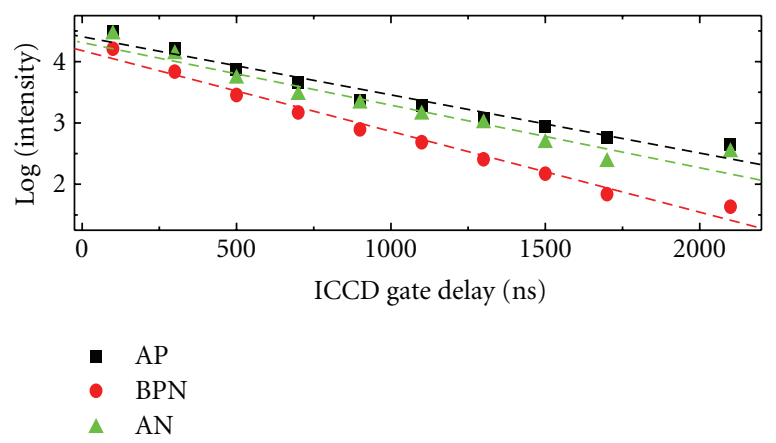

(b)

FIgURE 5: Intensity decay of (a) O $777.31 \mathrm{~nm}$ and (b) N $746.9 \mathrm{~nm}$ lines for AP, BPN, and AN samples with gate delay.

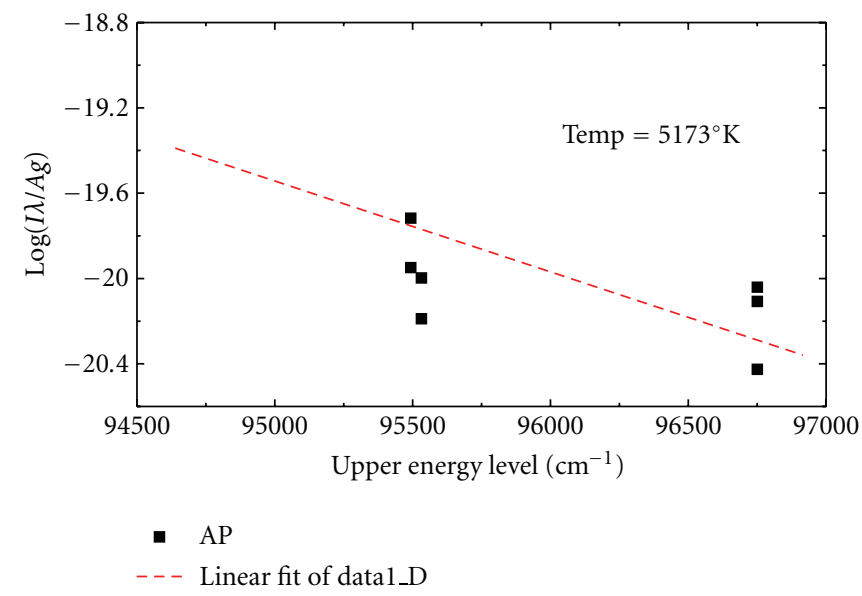

Figure 6: Typical Saha-Boltzmann plot obtained using the Nitrogen lines for estimating the plasma temperature. For a gate delay of 1300 ns and a gate width of $200 \mathrm{~ns}$ typical plasma temperature estimated was $5173^{\circ} \mathrm{K}$.

TABLE 2: Calculated decay constants for different atomic peaks in all three samples.

\begin{tabular}{lccc}
\hline \multicolumn{4}{c}{ Decay constants (numbers in $\mu \mathrm{s})$} \\
Element/wavelength $(\mathrm{nm})$ & AP & BPN & AN \\
\hline N-742.50 & 0.223 & 0.176 & 0.209 \\
N-744.34 & 0.266 & 0.187 & 0.237 \\
N-746.91 & 0.293 & 0.230 & 0.249 \\
N-821.69 & 0.412 & 0.384 & 0.315 \\
O-777.31 & 0.439 & 0.336 & 0.362 \\
O-844.74 & 0.314 & 0.266 & 0.286 \\
H-656.20 & 0.257 & 0.705 & 0.379 \\
\hline
\end{tabular}

for all the samples with gate delay in the case of gated LIBS. The ratios clearly showed an increased deviation in the initial part of delays and were closer to the actual stoichiometric ratio at gate delays beyond $1100 \mathrm{~ns}$ and up to 1900 ns. Line emission will be dominant and Continuum will die at these time scales. Moreover, the spectra which we obtain during this period are assumed to be in local thermal equilibrium (LTE). The ratios calculated for these compounds after $1 \mu$ s delay were clearly much closer to the stoichiometric lines of respective compounds (dashed lines in Figure 9). We have performed several trials and collected spectra with $1 \mu$ s time delay and $1 \mu$ s gate width for all the three samples. Table 3 shows the stoichiometric calculations for three compounds by considering the data from several independent spectra. The calculated mean ratio of all trails with standard deviation and \%RSD values are reviewed in Table 3. The mean ratio obtained for $\mathrm{O} / \mathrm{N}_{3}$ was found to be 3.90 in AP, 3.14 in BPN, and 2.84 in AN for the data obtained with gated spectrometer. Out of all the samples AP and BPN stoichiometric ratios matched very well with their actual stoichiometry. Ammonium nitrate is highly hygroscopic and, therefore, will absorb the moisture from atmosphere very quickly. This could, probably, be the reason for the high ratio obtained (actual ratio is 1.5). For the sample AP the three ratios $\mathrm{O} / \mathrm{N}_{1}, \mathrm{O} / \mathrm{N}_{2}$, and $\mathrm{O} / \mathrm{N}_{3}(3.82,3.70$, and 3.90) were in excellent agreement with the actual stoichiometric ratio of 4 , for $\mathrm{BPN} \mathrm{O} / \mathrm{N}_{2}$ (3.09) and $\mathrm{O} / \mathrm{N}_{3}$ (3.14) were in good agreement with actual stoichiometric ratio of 3 . That the ratio $\mathrm{O} / \mathrm{N}_{1}$ does not match with the stoichiometry needs to investigated. All the three ratios had minimal standard deviation and \%RSD. Therefore, we strongly feel that using this ratiometric method one could distinguish these samples at a preliminary level. Similar ratiometric approach was 


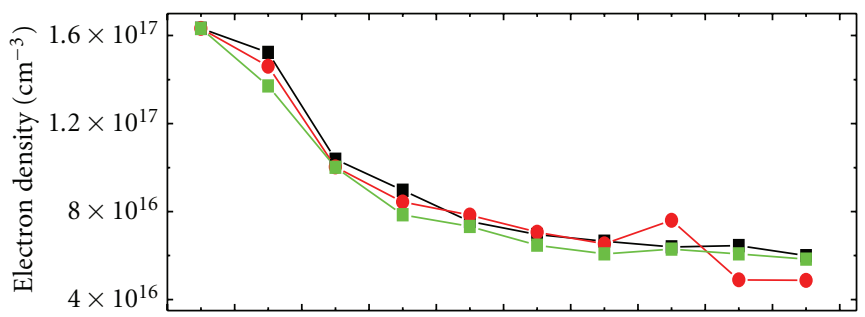

$\rightarrow \mathrm{AP}$
$\rightarrow \mathrm{BPN}$
$-\mathrm{AN}$

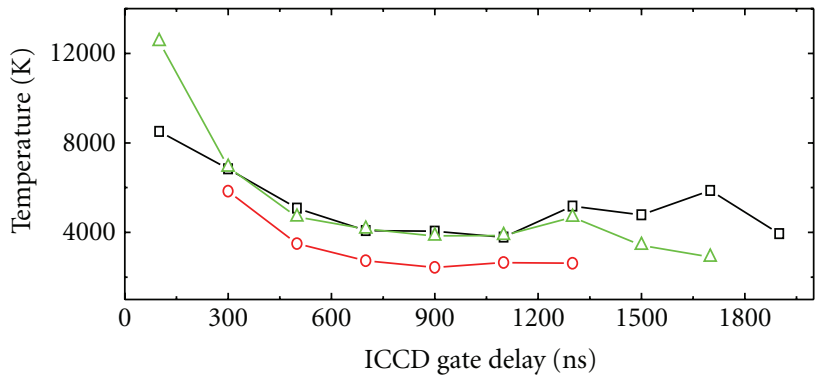

$\square-$ AP

$-0-$ BPN

$-\triangle$ AN

(a)

(b)

FIGURE 7: (a) Electron density and 7(b)temperature variation with ICCD time delay.

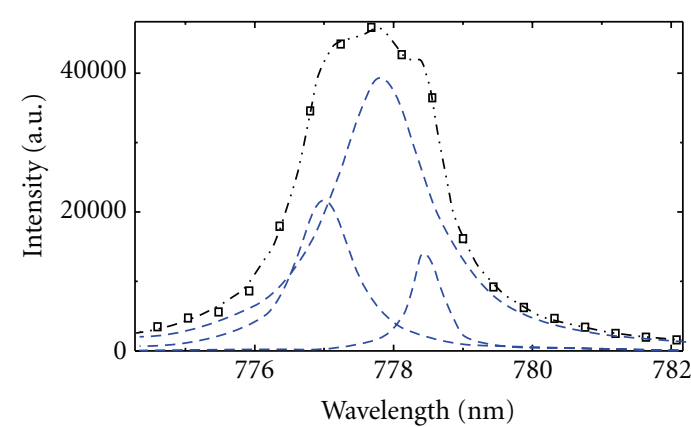

(a)

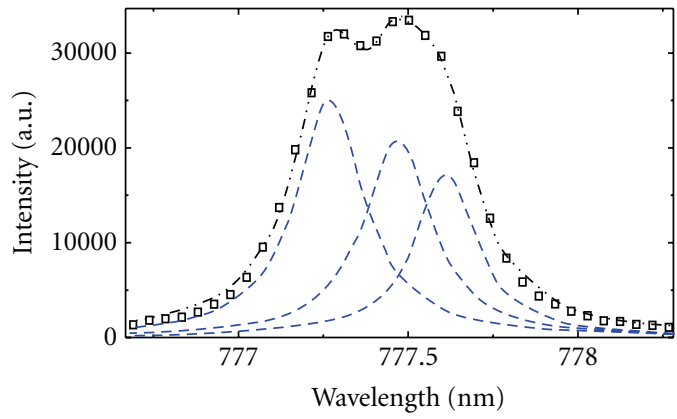

(c)

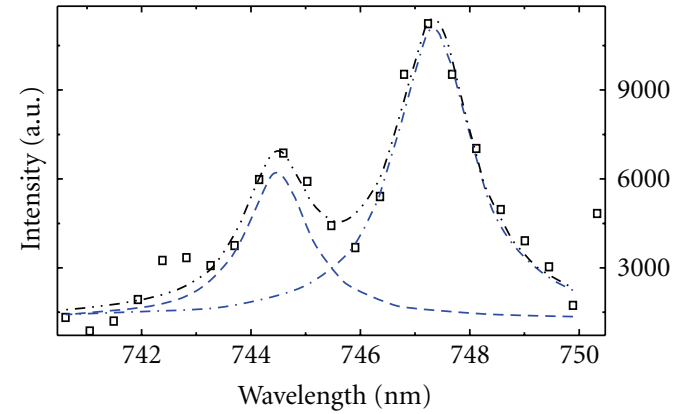

(b)

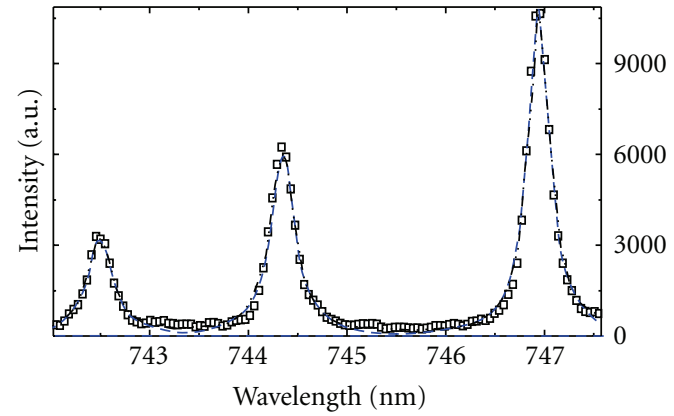

(d)

Figure 8: Typical Lorentzian fits for (a) Oxygen peaks near $777 \mathrm{~nm}$ and (b) Nitrogen peaks near 747 nm obtained with nongated (MAYA) spectrometer (c) and (d) are for O and N peaks obtained with gated (ICCD) spectrometer. Open squares and in (a), (b), and (c) are the observed peaks while the dotted (black) lines overall Lorentzian fits while the dashed (blue) lines are individual Lorentzian fits.

carried out with spectra collected with nongated spectrometer also. In case of nongated detection $\mathrm{O} / \mathrm{N}_{3}$ provided a close agreement with actual stoichiometric ratio for AP and BPN. The Nitrogen triplet peaks were not resolved fully, and hence we could not calculate all the 3 ratios. Only two ratios $\left(\mathrm{O} / \mathrm{N}_{2}\right.$ and $\left.\mathrm{O} / \mathrm{N}_{3}\right)$ were calculated. The calculated $\mathrm{O} / \mathrm{N}_{3}$ ratios found were 4.8 for AP, 3.44 for BPN, and 3.22 for AN. The standard deviation obtained was $0.94,1.18$, and 0.74 while $\%$ RSD was $19.63,34.18$, and 22.85, respectively, for AP, BPN, and $\mathrm{AN}$. That the $\mathrm{O} / \mathrm{N}_{2}$ ratio again did not match with actual stoichiometry needs to be investigated further and could mainly be attributed to the poorly resolved Oxygen and
Nitrogen peaks. The evaluated standard deviation and \%RSD values were less for gated data compared to nongated data.

Previous work [17] on nitrocompounds working on similar lines evaluated nine different ratios of $\mathrm{O} / \mathrm{N}$ among which only two were matching with the actual stoichiometry. In the present case we could fairly match the $\mathrm{O} / \mathrm{N}_{3}$ ratio even with nongated, data and at least two out of three ratios were in good agreement from the data obtained with gated technique. We feel that these results point a direction towards initial discrimination of such compounds. Combined with statistics-based correlation methods, one could achieve satisfactory and fool-proof classification schemes. As 
TABLE 3: Comparison of stoichiometric calculation of $\mathrm{O} / \mathrm{N}$ ratio of three inorganic compounds with gated and non-gated techniques.

\begin{tabular}{|c|c|c|c|c|c|c|c|c|}
\hline \multirow[b]{2}{*}{ Ratio } & \multicolumn{4}{|c|}{ Andor ICCD + mechelle spectrometer (gated) } & \multicolumn{4}{|c|}{ Ocean optics MAYA spectrometer (nongated) } \\
\hline & Stoi. & Mean & SD & $\%$ RSD & Stoi. & Mean & $\mathrm{SD}$ & $\%$ RSD \\
\hline & \multicolumn{8}{|c|}{ Ammonium perchlorate (AP) } \\
\hline O777.31/N742.50 & 4 & 3.82 & 0.63 & 16.45 & & - & - & - \\
\hline O777.31/N744.34 & 4 & 3.71 & 0.45 & 12.39 & 4 & 12.29 & 4.63 & 37.68 \\
\hline \multirow[t]{2}{*}{ O777.31/N746.91 } & 4 & 3.90 & 0.33 & 8.51 & 4 & 4.81 & 0.94 & 19.63 \\
\hline & \multicolumn{8}{|c|}{ Boron potassium nitrate (BPN) } \\
\hline O777.31/N742.50 & 3 & 2.24 & 0.48 & 21.47 & & - & - & - \\
\hline O777.31/N744.34 & 3 & 3.09 & 0.78 & 25.17 & 3 & 7.84 & 4.94 & 63.00 \\
\hline \multirow[t]{2}{*}{ O777.31/N746.91 } & 3 & 3.14 & 0.40 & 12.86 & 3 & 3.44 & 1.18 & 34.18 \\
\hline & \multicolumn{8}{|c|}{ Ammonium nitrate (AN) } \\
\hline O777.31/N742.50 & 1.5 & 3.04 & 0.49 & 16.14 & & - & - & - \\
\hline O777.31/N744.34 & 1.5 & 2.90 & 0.16 & 5.43 & 1.5 & 6.17 & 1.92 & 31.02 \\
\hline O777.31/N746.91 & 1.5 & 2.84 & 0.13 & 4.44 & 1.5 & 3.22 & 0.74 & 22.85 \\
\hline
\end{tabular}

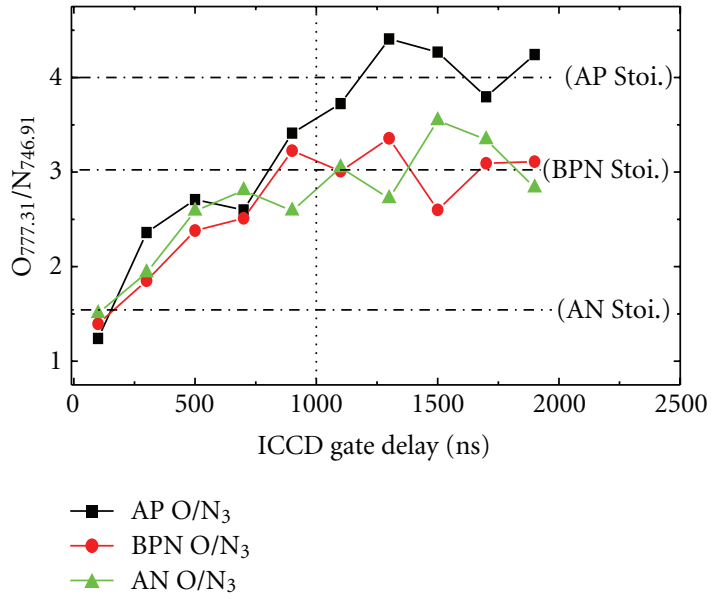

FIGURe 9: Time evolution of the $\mathrm{O}(777.31 \mathrm{~nm}) / \mathrm{N}_{3}(746.91 \mathrm{~nm})$ ratio. Dashed lines represent the actual stoichiometric ratio of three compounds.

pointed out in earlier works [17], statistical techniques of linear correlation and principal component analysis for the identification of compounds could be included to improve the level of reliability provided by this data. We are in the process of recording the LIBS data of various other nitrobased molecules, using a higher-resolution spectrometer, in an attempt to strengthen our arguments for the case of using nongated spectrometer in such analyses.

\section{Conclusions}

LIBS studies have been performed on AP, AN, and BPN to weigh the prospects of nongated collection scheme against the gated light collection scheme. Two of these were nitrobased compounds while the third one was simple inorganic molecule. $\mathrm{O} / \mathrm{N}$ ratios have been calculated from the LIBS spectra. In the case of data obtained with gated spectrometer for $\mathrm{AP}$, all the three $\mathrm{O} / \mathrm{N}$ ratios demonstrated a good agreement with the actual stoichiometric $(\mathrm{O} / \mathrm{N})$ ratio while for $\mathrm{BPN}$ two of the $\mathrm{O} / \mathrm{N}$ ratios matched with the actual values. We observed that, when the spectra was recorded after a delay time of $1000 \mathrm{~ns}$, the calculated $\mathrm{O} / \mathrm{N}$ ratios were in good concurrence with actual stoichiometry values. In the nongated scheme the calculated $\mathrm{O} / \mathrm{N}_{3}$ ratio values were in fine agreement with the actual stoichiometry of sample. The work successfully demonstrates the merits of using simple, yet cost effective, nongated spectrometers compared to the expensive gated spectrometer detection.

\section{Acknowledgments}

The authors acknowledge the Defense Research and Development Organization, India for providing the financial support needed for the experimental facility. They acknowledge the samples provided by HEMRL, Pune, India, and Dr. A. A. Vargeese.

\section{References}

[1] F. Y. Yueh, J. P. Singh, and H. Zhang, Encyclopedia of Analytical Chemistry, John Wiley \& Sons, London, UK, 2000.

[2] K. E. Eseller, F. Y. Yueh, and J. P. Singh, "Non-intrusive, on-line, simultaneous multi-species impurity monitoring in hydrogen using LIBS," Applied Physics B, vol. 102, no. 4, pp. 963-969, 2011.

[3] N. C. Dingari, I. Barman, M. A. Kumar, S. P. Tewari, and G. M. Kumar, "Incorporation of support vector machines in the LIBS toolbox for sensitive and robust classification amidst unexpected sample and system variability," Analytical Chemistry, vol. 84, pp. 2686-2694, 2012.

[4] J. L. Gottfried, F. C. de Lucia Jr., C. A. Munson, and A. W. Miziolek, "Double-pulse standoff laser-induced breakdown spectroscopy for versatile hazardous materials detection," Spectrochimica Acta B, vol. 62, no. 12, pp. 1405-1411, 2007.

[5] I. V. Cravetchi, M. Taschuk, G. W. Rieger, Y. Y. Tsui, and R. Fedosejevs, "Spectrochemical microanalysis of aluminum 
alloys by laser-induced breakdown spectroscopy: identification of precipitates," Applied Optics, vol. 42, no. 30, pp. 61386147, 2003.

[6] A. C. Samuels, F. C. de Lucia Jr., K. L. McNesby, and A. W. Miziolek, "Laser-induced breakdown spectroscopy of bacterial spores, molds, pollens, and protein: initial studies of discrimination potential," Applied Optics, vol. 42, no. 30, pp. 6205-6209, 2003.

[7] M. Hoehse, D. Mory, S. Florek, F. Weritz, I. Gornushkin, and U. Panne, "A combined laser-induced breakdown and Raman spectroscopy Echelle system for elemental and molecular microanalysis," Spectrochimica Acta B, vol. 64, no. 11-12, pp. 1219-1227, 2009.

[8] Y. Dikmelik, C. McEnnis, and J. B. Spicer, "Femtosecond and nanosecond laser-induced breakdown spectroscopy of trinitrotoluene," Optics Express, vol. 16, no. 8, pp. 5332-5337, 2008.

[9] A. W. Miziolek, V. Palleschi, and I. Schechter, Laser-Induced Breakdown Spectroscopy (LIBS) Fundamentals and Applications, Cambridge University Press, New York, NY, USA, 2006.

[10] D. A. Cremers and L. J. Radziemski, Handbook of LaserInduced Breakdown Spectroscopy, John Wiley \& Sons, London, UK, 2006.

[11] J. P. Singh and S. N. Thakur, Laser-Induced Breakdown Spectroscopy, Elsevier Science, Amsterdam, The Netherlands, 2007.

[12] F. J. Fortes and J. J. Laserna, "The development of fieldable laser-induced breakdown spectrometer: no limits on the horizon," Spectrochimica Acta B, vol. 65, no. 12, pp. 975-990, 2010.

[13] N. Kawahara, J. L. Beduneau, T. Nakayama, E. Tomita, and Y. Ikeda, "Spatially, temporally, and spectrally resolved measurement of laser-induced plasma in air," Applied Physics B, vol. 86, no. 4, pp. 605-614, 2007.

[14] S. Sreedhar, S. V. Rao, P. P. Kiran, S. P. Tewari, and G. M. Kumar, "Stoichiometric analysis of ammonium nitrate and ammonium perchlorate with nanosecond laser induced breakdown spectroscopy," in Chemical, Biological, Radiological, Nuclear, and Explosives (CBRNE) Sensing XI, A. Fountain III and P. J. Gardner, Eds., vol. 7665 of Proceedings of SPIE, Orlando, Fla, USA, 2010.

[15] S. Sreedhar, M. A. Kumar, G. M. Kumar, P. P. Kiran, S. P. Tewari, and S. V. Rao, "Laser-induced breakdown spectroscopy of RDX and HMX with nanosecond, picosecond, and femtosecond pulses," in Chemical, Biological, Radiological, Nuclear, and Explosives (CBRNE) Sensing XI, A. W. Fountain III and P. J. Gardner, Eds., vol. 7665 of Proceedings of SPIE, Orlando, Fla, USA, 2010.

[16] K. E. Eseller, F. Y. Yueh, and J. P. Singh, "Laser-induced breakdown spectroscopy measurement in methane and biodiesel flames using an ungated detector," Applied Optics, vol. 47, no. 31, pp. G144-G148, 2008.

[17] S. Rai, A. K. Rai, and S. N. Thakur, "Identification of nitrocompounds with LIBS," Applied Physics B, vol. 91, no. 3-4, pp. 645-650, 2008.

[18] S. Rai, A. K. Rai, I. M. L. Das, and K. C. Tripathi, "Implementation of statistical methods on LIBS data for classification of residues of energetic materials (nitro compounds)," Advanced Materials Letters, vol. 2, pp. 32-37, 2011.

[19] M. A. Kumar, S. Sreedhar, I. Barman et al., "Laser-induced breakdown spectroscopy-based investigation and classification of pharmaceutical tablets using multivariate chemometric analysis," Talanta, vol. 87, pp. 53-59, 2011.
[20] J. Anzano, R. J. Lasheras, B. Bonilla, and J. Casas, "Classification of polymers by determining of $\mathrm{C}_{1}: \mathrm{C}_{2}: \mathrm{CN}: \mathrm{H}: \mathrm{N}: \mathrm{O}$ ratios by laser-induced plasma spectroscopy (LIPS)," Polymer Testing, vol. 27, no. 6, pp. 705-710, 2008.

[21] F. C. de Lucia Jr. and J. L. Gottfried, "Characterization of a series of nitrogen-rich molecules using laser induced breakdown spectroscopy," Propellants, Explosives, Pyrotechnics, vol. 35, no. 3, pp. 268-277, 2010.

[22] C. L. Moreno, S. Palanco, J. J. Laserna et al., "Test of a stand-off laser-induced breakdown spectroscopy sensor for the detection of explosive residues on solid surfaces," Journal of Analytical Atomic Spectrometry, vol. 21, no. 1, pp. 55-60, 2006.

[23] V. Sturm and R. Noll, "Laser-induced breakdown spectroscopy of gas mixtures of air, $\mathrm{CO}_{2}, \mathrm{~N}_{2}$, and $\mathrm{C}_{3} \mathrm{H}_{8}$ for simultaneous $\mathrm{C}$, $\mathrm{H}, \mathrm{O}$, and N measurement," Applied Optics, vol. 42, no. 30, pp. 6221-6225, 2003.

[24] J. L. Gottfried, F. C. de Lucia Jr., C. A. Munson, and A. W. Miziolek, "Strategies for residue explosives detection using laser-induced breakdown spectroscopy," Journal of Analytical Atomic Spectrometry, vol. 23, no. 2, pp. 205-216, 2008.

[25] E. J. Judge, G. Heck, E. B. Cerkez, and R. J. Levis, "Discrimination of composite graphite samples using remote filamentinduced breakdown spectroscopy," Analytical Chemistry, vol. 81, no. 7, pp. 2658-2663, 2009.

[26] H. Estupinan, D. Y. Pena, Y. O. Garcia, R. Cabanzo, and MejiaOspino, "Stoichiometry analysis of titanium oxide coating by LIBS," The European Physical Journal D, vol. 53, pp. 69-73, 2009.

[27] D. Mirell, O. Chalus, K. Peterson, and J. C. Diels, "Remote sensing of explosives using infrared and ultraviolet filaments," Journal of the Optical Society of America B, vol. 25, no. 7, pp. B108-B111, 2008.

[28] P. Lucena, A. Doña, L. M. Tobaria, and J. J. Laserna, "New challenges and insights in the detection and spectral identification of organic explosives by laser induced breakdown spectroscopy," Spectrochimica Acta B, vol. 66, no. 1, pp. 12-20, 2011.

[29] H. Zhang, F. Y. Yueh, and J. P. Singh, "Laser-induced breakdown spectrometry as a multimetal continuous-emission monitor," Applied Optics, vol. 38, pp. 1459-1466, 1999.

[30] J. L. Gottfried, F. C. de Lucia Jr., C. A. Munson, and A. W. Miziolek, "Discrimination of explosive residues on organic and inorganic substrates using laser-induced breakdown spectroscopy," Journal of Analytical Atomic Spectrometry, vol. 24, no. 3, pp. 288-296, 2009.

[31] J. L. Gottfried, F. C. de Lucia Jr., C. A. Munson, and A. W. Miziolek, "Laser-induced breakdown spectroscopy for detection of explosives residues: a review of recent advances, challenges, and future prospects," Analytical and Bioanalytical Chemistry, vol. 395, no. 2, pp. 283-300, 2009.

[32] F. C. de Lucia Jr., J. L. Gottfried, C. A. Munson, and A. W. Miziolek, "Multlvariate analysis of standoff laserinduced breakdown spectroscopy spectra for classification of explosive-containing residues," Applied Optics, vol. 47, no. 31, pp. G112-G121, 2008.

[33] F. C. de Lucia Jr., A. C. Samuels, R. S. Harmon et al., "Laserinduced breakdown spectroscopy (LIBS): a promising versatile chemical sensor technology for hazardous material detection," IEEE Sensors Journal, vol. 5, no. 4, pp. 681-689, 2005.

[34] NIST database of atomic spectral data, http://physics.nist .gov/PhysRefData/ASD.

[35] H. R. Griem, Plasma Spectroscopy, McGraw-Hill, New York, NY, USA, 1964. 

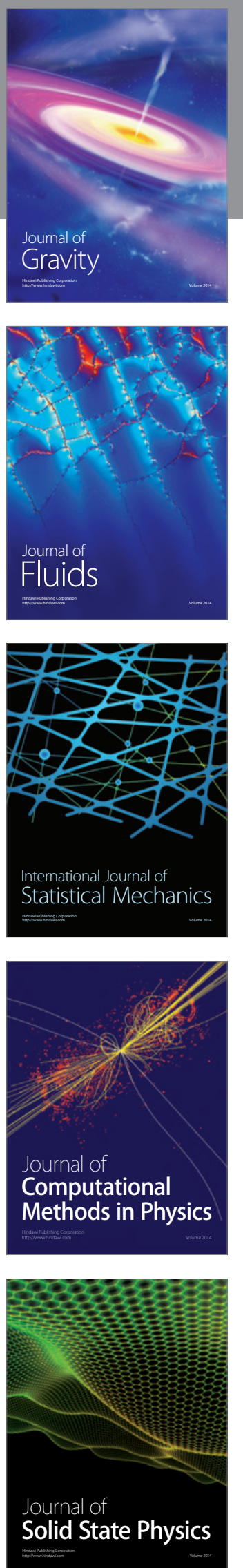
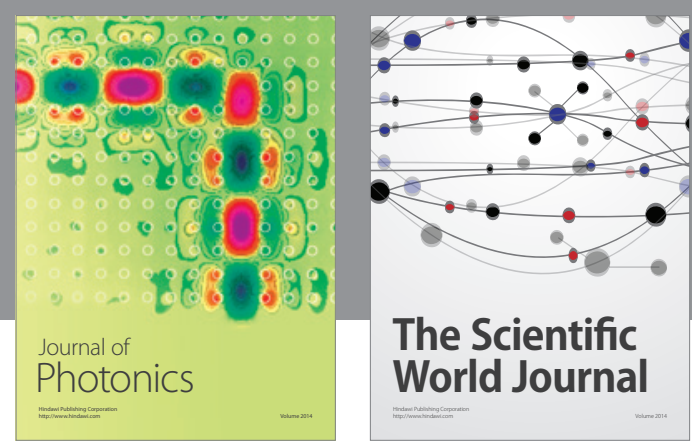

The Scientific World Journal

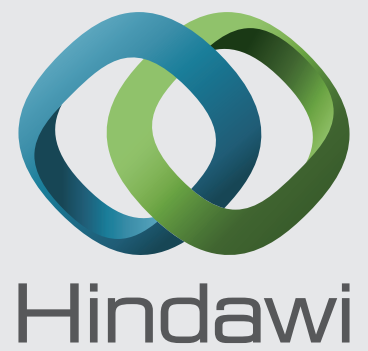

Submit your manuscripts at http://www.hindawi.com
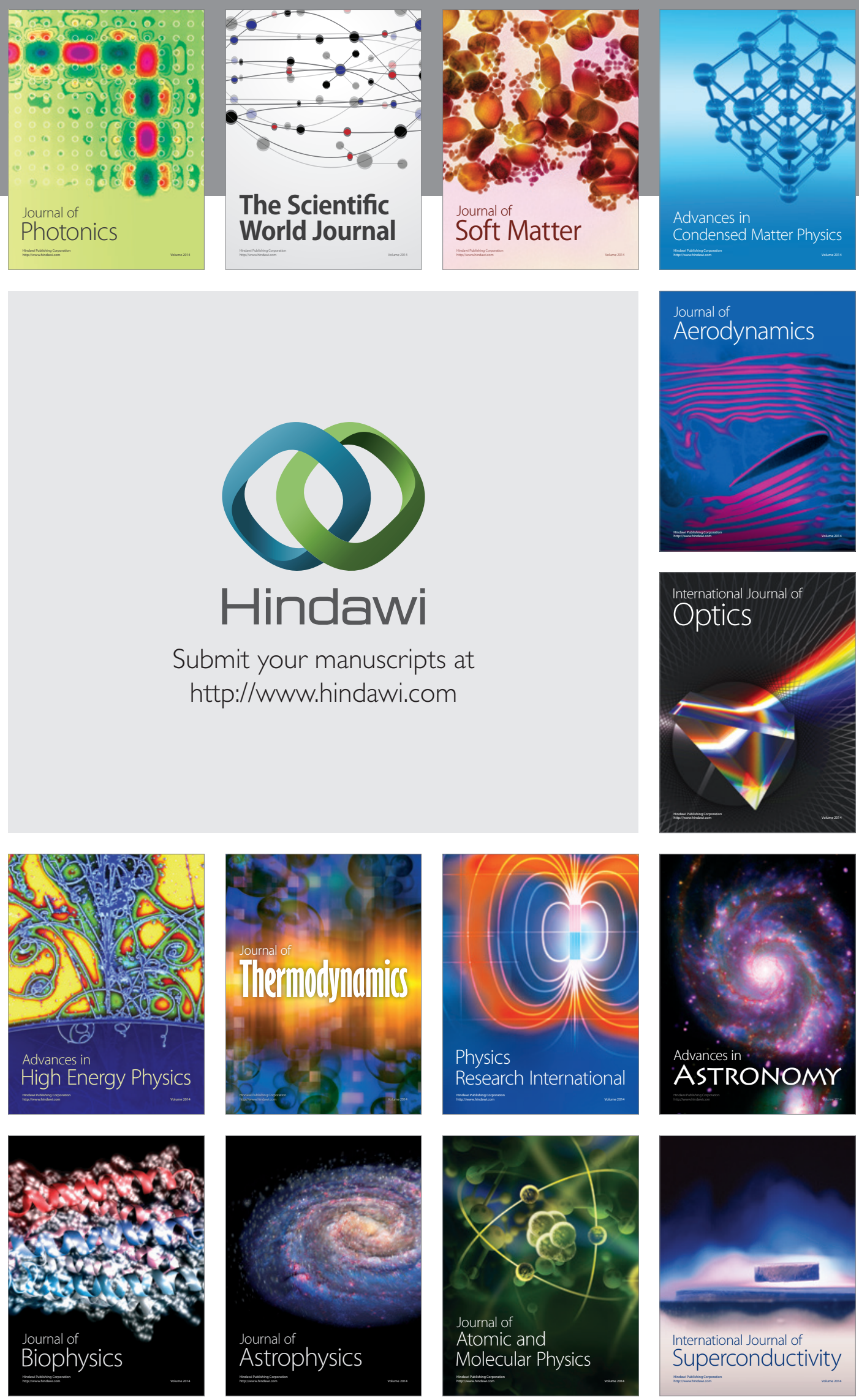
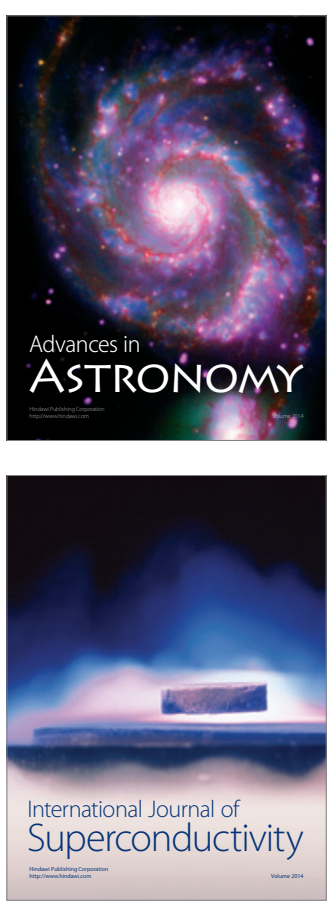